\title{
Wischen statt blättern!
}

\author{
Was Sie gerade auf Papier gedruckt in den Händen halten, könnten Sie auch online auf Ihrem Tablet \\ lesen, denn ab sofort gibt es Ihre "InFo Onkologie“ auch als ePaper: Es steht auf SpringerMedizin.de, \\ dem Fachportal für Ärzte, kostenlos zum Download bereit. Dort finden Sie auch das Archiv der Zeit- \\ schrift und noch vieles mehr ...
}

„InFo Onkologie“ ist nur eine von 110 deutschsprachigen Fachzeitschriften und 540 internationalen Publikationen, deren Inhalte auf SpringerMedizin.de gebündelt online zur Verfügung gestellt werden. Auf diese Weise entsteht ein gigantischer Fundus an medizinischem Wissen, in dem mit der Suchfunktion gezielt recherchiert werden kann - etliche Inhalte sind dabei sogar kostenfrei zugänglich.

Darüber hinaus berichtet das Fachportal tagesaktuell aus Medizin und Forschung und hält unter dem Reiter „CME“ ein laufend aktualisiertes Angebot von über 600 zertifizierten Fortbildungskursen bereit - darunter auch die CME-Module aus „InFo Onkologie“.

\section{Portabel und kostenlos}

Damit „InFo Onkologie“ in dieser Datenflut nicht verlorengeht, gibt es eine eigene Startseite, auf der alle Inhalte und Informationen zur Zeitschrift verlinkt sind. Diese erreichen Sie zum Beispiel über den Menüpunkt „Zeitschriften“. Dort angekommen können Sie über das Archiv auf alle Ausgaben der letzten Jahre zugreifen und gezielt einzelne Beiträge online lesen.

Neu ist, dass Sie Ihre Zeitschrift auch digital im gewohnten Magazinlayout als ePaper lesen können. Dieses bietet neben einer Suchmaske auch ein interaktives Inhaltsverzeichnis, sodass Sie schnell zum gewünschten Beitrag gelangen. Zoomfunktion und Seitenübersicht erleichtern das Lesen und die Navigation durch die Ausgabe. Das ePaper wurde für die Tabletnutzung optimiert, sodass Sie unkompliziert mit dem Finger durch die Magazinseiten „blättern“ können. Außerdem gibt es eine Download-Funktion, mit deren Hilfe Sie „InFo Onkologie“ überallhin mitnehmen und offline lesen können. Die Ergänzung unserer Printausgabe durch diese digitalen Tools lässt Sie Ihre Lesezeit individuell einteilen und optimal nutzen.

Der Zugang zu Beiträgen und zum ePaper von „InFo Onkolo-

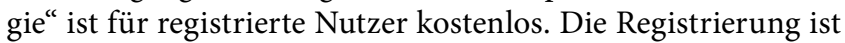
allerdings erforderlich, da der Zugang zum Portal auf Ärzte beschränkt ist. Als Nachweis kann die einheitliche Fortbildungsnummer (EFN) angegeben oder auch die Approbationsurkunde vorgelegt werden. Außerdem können Sie bei der Registrierung Ihre Facharztrichtung und Ihre Interessensgebiete angeben, sodass unsere Themenvielfalt gezielt auf Sie zugeschnitten wird.

\section{Umfangreiches Online-Angebot}

Einmal registriert haben Sie online Zugang zu SpringerMedizin. de sowie zu ÄrzteZeitung.de und können an den CME-Modulen Ihrer Zeitschriften teilnehmen. Ideal für Entdeckungsreisen durch SpringerMedizin.de ist das auf 30 Tage befristete e.MedTestabo, mit dem Sie Zugriff auf alle Inhalte haben. Dazu finden Sie weitere Informationen unter www.springermedizin.de/ eMed. Auf der nächsten Seite erfahren Sie Schritt für Schritt, wie Sie zum ePaper gelangen. red.

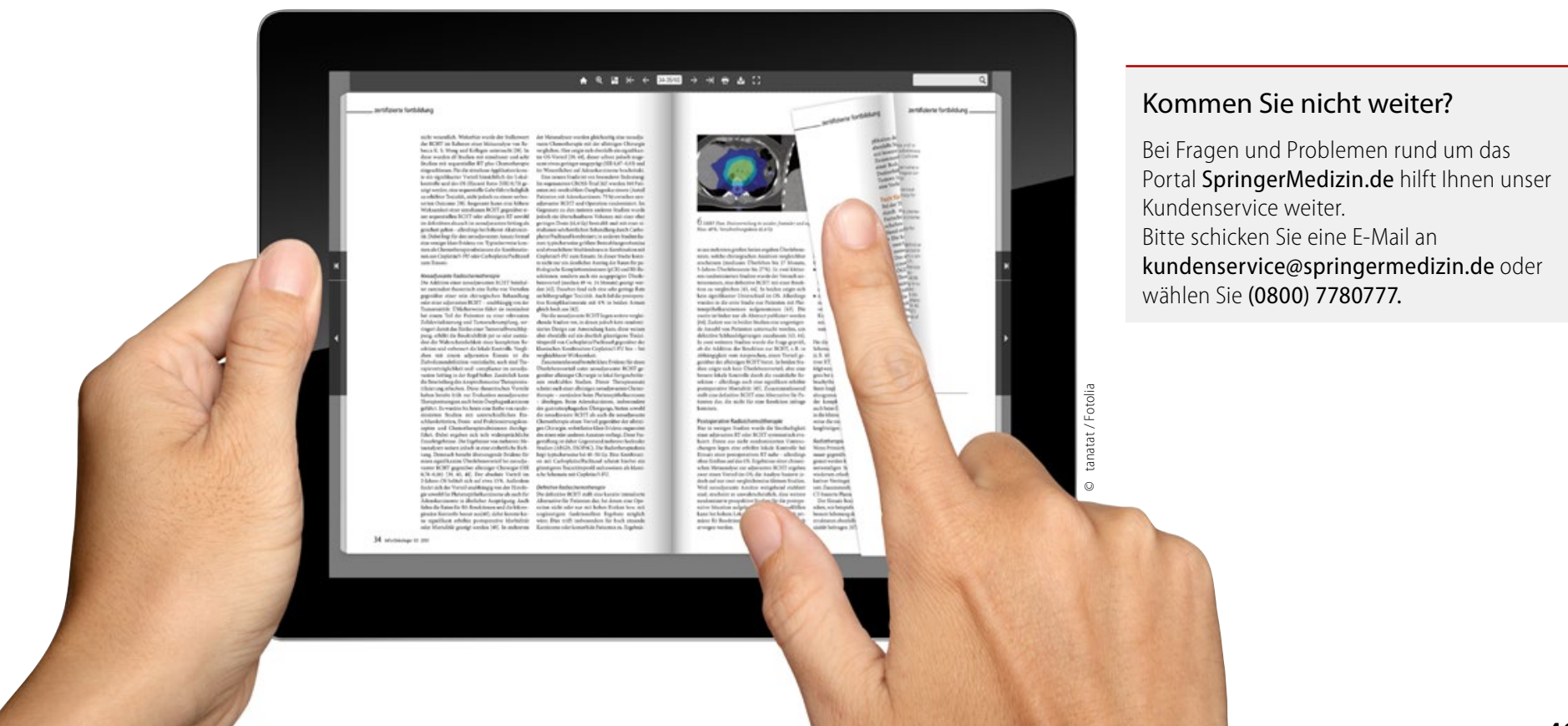

